
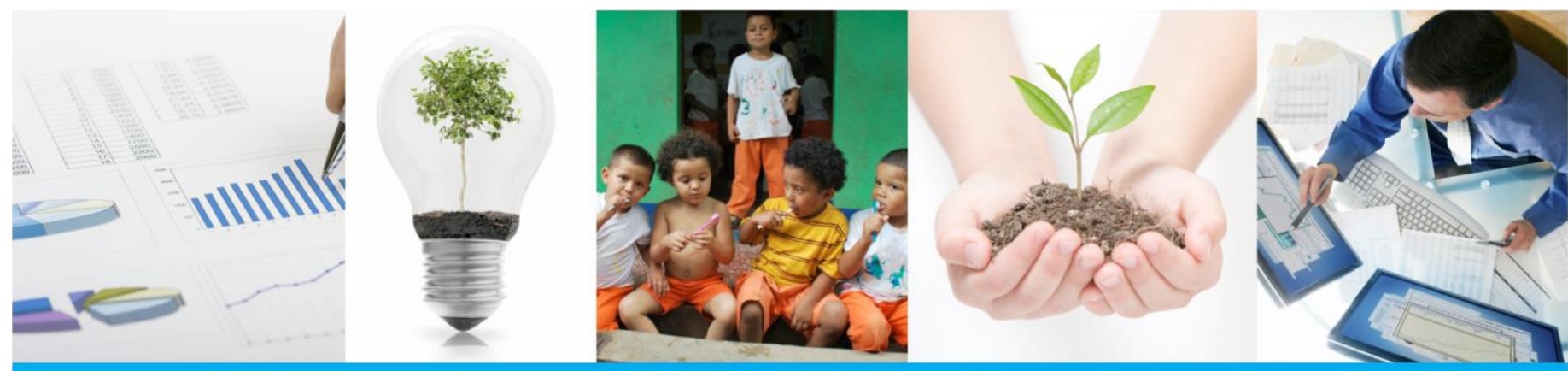

Systematising serendipity for big science infrastructures: the ATTRACT project

Jonathan Wareham

Laia Pujol Priego

Markus Nordberg

Pablo Garcia Tello 


\section{ESADE}

Ramon Lull University

\section{ESADE Working Papers Series}

Available from ESADE Knowledge

Web: www.esadeknowledge.com

(c) ESADE

Avda. Pedralbes, 60-62

E-08034 Barcelona

Tel.: +34 932806162

ISSN 2014-8135

Depósito Legal: B-4761-1992 


\title{
Systematising serendipity for big science infrastructures: the ATTRACT project
}

\author{
Jonathan Wareham \\ Laia Pujol Priego \\ ESADE, Ramon Llull University \\ jonathan.wareham@esade.edu \\ laia.pujol@esade.edu \\ Markus Nordberg \\ Pablo Garcia Tello \\ CERN-European Organization for Nuclear Research \\ markus.nordberg@cern.ch \\ pablo.garcia.tello@cern.ch
}

\begin{abstract}
The potential of big science research infrastructures to make contributions far beyond their scientific purview has long been acknowledged. However, less consensus exists about the specific mechanisms with which such value can realised. This paper describes the ATTRACT project. A novel approach funded with $€ 20$ million by the European Commission Horizon 2020 programme, ATTRACT ${ }^{1}$ represents a consortium of leading European scientific centres, academic institutions, and industry associations formed to harness their world-class scientific instrumentation technologies towards entrepreneurship within European economies. ATTRACT will award 170 projects centred on breakthrough imaging and detection technologies $€ 100,000$ each to develop a proof-of-concept within one year. With the goal of scaling a select few of the most promising projects, ATTRACT will facilitate additional iterations of public and private funding along with relevant commercial and legal support to bridge the gap between supply-push and demand-pull innovation policy instruments. The paper describes the ATTRACT project: its motivation, philosophy, design, and results to date.
\end{abstract}

\footnotetext{
${ }^{1}$ ATTRACT members include: the European Organization for Nuclear Research (CERN), European Molecular Biology Laboratory (EMBL), European Southern Observatory (ESO), European Synchrotron Radiation Facility (ESRF), European X-Ray Free Electron Laser Facility (European XFEL), and the Institut Laue-Langevin (ILL), Aalto University, ESADE Business School, and the European Industrial Research Management Association (EIRMA).
} 


\subsection{Introduction}

It is generally acknowledged that most big science infrastructures have social, cultural, and economic reach that extends far beyond their direct scientific purview. However, uncertainty remains as to what these effects are, how they should be measured, and how managers and policymakers might best capture them. In this paper, we describe the ATTRACT project, an initiative funded by the European Union within the Horizon 2020 Framework Programme with $€ 20$ million to create a co-innovation ecosystem (Autio 2018) that uses fundamental research as an engine for industrial innovation.

The premises of the ATTRACT project are as follows. To conduct research at the very forefront of science, big science infrastructures need to develop next-generation breakthrough detection and imaging instrumentation that represents the vanguard of technology engineering. Detection and imaging technologies at big science centres are very diverse. During WWII and the Cold War, investments in big scientific research infrastructures were initially motivated by geopolitical uncertainty, and consequently, centred on nuclear physics and nuclear weaponry.

However, today the technologies of big science are substantially more versatile: traditional particle accelerators work alongside systems for synchrotron radiation, neutron scattering, free electron lasers, super-computation, and astronomical \& light and radiation detection. The empirical scope is substantially wider, including astrophysics, materials sciences, chemistry, energy, condensed matter physics, nanoscience, biology, biotechnology, and pharmacology. Given their extreme sophistication and required investment levels, research infrastructures are normally funded by taxpayers via national ministries or funding agencies - often in pan-national consortia. As such, it bears upon policymakers to seek mechanisms to optimise the potential socioeconomic value of these public investments. History has demonstrated that big science technologies can be leveraged in alternative uses; that is, products and services that are outside their original scientific purview (e.g. oncological isotopes from synchrotrons, or HTML and touchscreens from CERN.) Further, the path to realising value in new applications can be accidental or serendipitous. The overarching goal of ATTRACT is to create an ecosystem where Europe's leading scientific research infrastructures work with industry to realise the untapped potential of its detection and imaging technologies. It recognises that the full potential of these detection and imaging technologies is unknown and capturing their value will require both stimulating exploration and simultaneously fostering commercial development through risk absorption and support. In effect, ATTRACT seeks to embrace the serendipitous discovery of breakthrough applications in a systemic fashion; to leverage the technologies developed by leading European science research infrastructures towards sustainable businesses and greater economic returns for the European economy. It will 
stimulate this cycle by seed-funding 170 projects with $€ 100,000$ each. In doing so, it will provide the de-risking, evaluation, and developmental support that can make a selected group of these projects attractive at a later stage to venture capital and private investment.

The article proceeds by expanding on the history of big science, the polemics of its underlying social value, and specific measures and mechanisms employed to understand how the design, construction, and operation of scientific research infrastructures can foster innovation. We then proceed to describe the ATTRACT project, its philosophy, structure, objectives, and results to date. We conclude with some initial observations concerning its process and outcomes and describe trajectories for future initiatives concerning big science and socioeconomic value.

\subsection{Definition \& history}

Crude descriptors of big science include big budgets, big machines, big staffs, big laboratories, and big politics. A more subtle definition by Florio and Sirtori (2016) is that big science infrastructures are institutions with: a) high capital intensity, b) long-lasting facilities or networks, c) operating in monopoly or oligopoly conditions affected by externalities, d) who produce social benefits via the generation of new knowledge (either pure or applied). Well-known big science endeavours currently in construction or operation include (alphabetically) ${ }^{2}$ : BRAIN (Brain Research through Advancing Innovation and Neurotechnologies); Cancer Moonshot; European Extremely Large Telescope; European Spallation Source; Human Brain Project; Human Genome Project; International Space Station; International Thermonuclear Experimental Reactor; Large Hadron Collider at CERN; Precision Medicine Initiative; and the Square Kilometer Array. It should be noted that the capital intensity of these projects varies considerably. Where some such as CERN, European Extremely Large Telescope, International Space Station, or International Thermonuclear Experimental Reactor are extremely capital intensive, others such as the Human Brain Project or the Human Genome Project are more computationally intensive and require different types of investment.

The rise of big science is often associated with the Manhattan Project and the numerous technological innovations that were enhanced during WWII such as radar and wireless communication. However, as argued by Giudice (2012), the evolution of big science began far earlier in the twentieth century with such examples as the factory-like conditions where Heike Kamerlingh Onnes made seminal discoveries on superfluidity and superconductivity in the early 1900s, or the Wilson Observatory, completed in 1917 and made famous by Edwin Hubble. What began to characterise research as big science was how it differed from the ideal of the lone genius

\footnotetext{
${ }^{2}$ See for an expanded list: https://en.wikipedia.org/wiki/List of megaprojects\#Science projects
} 
in the laboratory with simple table-top experiments. This new model of scientific exploration was fully institutionalised by Ernest Orlando Lawrence with the development of cyclotron at UC Berkeley: a device for accelerating nuclear particles to very high velocities to bombard, disintegrate, and form completely new elements and radioactive isotopes. His first cyclotron was a simple 4-inch device that could be held in the human hand. With the success of his first model, Lawrence designed larger versions that could achieve greater energy levels: a 27-inch $4.8 \mathrm{MeV}$ machine (1932), a 37-inch $8 \mathrm{MeV}$ machine (1937), a 60-inch $16 \mathrm{MeV}$ machine (1939), and 184-inch synchrocyclotron (1945) (Yarris n.d.). The scientific contributions of Lawrence to physical chemistry earned him a Nobel prize in 1939 (Nobel.org n.d.). However, Lawrence is most often credited with how he fundamentally changed the way research in his scientific discipline was conducted. With each subsequent generation of the cyclotron, a larger number of physicists, engineers, and chemists were needed for construction, operation, and maintenance. More importantly, he advanced a form of team-based, collaborative science that contrasted with the isolated model of 'smaller science' ${ }^{3}$ (Hiltzik 2015) and later matured into large research teams with hundreds of scientists and engineers. This new kind of industrialised science eventually propagated to other American and European universities and was facetiously called the 'Cyclotron Republic' by Lawrence's numerous admirers and rivals (Hiltzik 2015).

A serendipitous by-product of Lawrence's Rad-Lab at UC Berkeley was that even the earlystage 27 and 37-inch cyclotrons could produce radioactive isotopes at unprecedented rates (Hiltzik 2015). Beyond physics research, a number of foundations and philanthropists expressed interest in the isotopes for cancer treatment. As the economic stagnation of the Great Depression forced many research philanthropies to curtail funding for basic research, money for medical research was less constrained. With the help of his brother John Lawrence (a medical doctor who became director of the university's Medical Physics Laboratory), the relentlessly pragmatic Ernest was able re-craft the cyclotron's narrative to court funders intrigued by the potential of important isotopes such as sodium-24 (made from rock salt). In a Faustian spirit, the Rad-Lab metaphorically produced oncology-focused isotopes by day, while discretely conducting basic research by night. And while many on the Rad Lab team bemoaned the fact that commitments to medical research hindered advancement in fundamental physics, this shrewd strategy enabled Lawrence to fund his constantly moving targets of higher energy levels that required larger more sophisticated

\footnotetext{
${ }^{3}$ Quoting Luis Alvarez in Hiltzik (2015): There were no doors inside the Rad Lab. 'Its central focus was the cyclotron, on which everyone worked and which belonged to everyone equally (though perhaps more to Ernest). Everyone was free to borrow or use everyone else's equipment or, more commonly, to plan a joint experiment'. The team approach to physics, Alvarez judged, was 'Lawrence's greatest invention'. (Hiltzik 2015:129-30).
} 
hardware, complex operating organisations, and generated unprecedented costs. This tactic further institutionalised the future relationship between big science and big funders, be they philanthropies, national ministries of defence or energy, or increasingly, supranational-coalitions (Crease et al. 2016).

\subsection{Big science and geopolitics}

The close relationship between scientific policy and national defence was considered entirely natural after the experience of WWII and was extended into the cold war. Motivated primarily by military and global political concerns, technological superiority was considered a central element of geopolitical competition (Galison and Hevly 1992). This was not limited to military research, although the defence industry was certainly a central protagonist. Espoused in the famous report of Vannevar Bush, Science: The Endless Frontier (Bush 1945), basic research was not only good for fundamental science but generated applied engineering and technologies that translated to products, spin-offs, jobs, and overall economic prosperity that benefited all social classes. The 'Bush legacy' (Wilson 1991) was further catalysed by the successful leap-start of the Soviet space programme, an event that galvanised the American public to approve the astronomical funding levels of the American space programme with little concern for its scientific merit; there was a technological gap between the USA and USSR, and, like the Manhattan Project, this was perceived as a severe existential threat that could only be remedied by massive investments in basic, applied, and ever-bigger science (Giudice 2012).

\subsection{A critical evaluation}

Perhaps the most seminal discourse that questioned how limited resources were prioritised towards big scientific infrastructure investments was that of Alvin Weinberg, who expressed concern in his initial article in Science in 1961 (Weinberg 1961) and focused the debate with two polemic articles published in Minerva in 1963 and 1964 (Weinberg 1963, 1964). As director for the Oak Ridge National Laboratory (where uranium was enriched for the atomic bomb in its early years), his purpose was not to be antagonistic towards science; he was a staunch defender of basic, non-directed science. Rather, his goal was to establish some criteria for which investments in big science could be evaluated against alternative social priorities (Hellström and Jacob 2012). His concern was that big science had become a bloated self-serving institution of bureaucracy and complacency, disconnected from more basic human and social needs (Crease et al. 2016).

The debate initiated by Weinberg is still relevant today (Hellström and Jacob 2012), although it has evolved into the new context of big science. Since the cold war, the perception of existential geopolitical threats is a more disperse narrative. As a result, investment in big science 
motivated by national security or geopolitical stability has decreased. This has weakened the sacrosanct link between nuclear physics, weapons research, and geopolitical security, and as a consequence, reduced the primacy of fundamental physics (Galison \& Hevly, 1992; Hiltzik, 2015). Secondly, the tenacious success of the Standard Model has left aspiring physicists scrambling for new avenues to conduct physics, leading them to astrophysics and cosmology, as well as more distant fields in biology and life sciences (Galison 2016). In addition, the nature of big science infrastructures has become more heterogeneous; today we now see traditional particle accelerators and nuclear reactors work alongside synchrotron radiation, neutron scattering, and free electron laser facilities, where the empirical scope has widened to materials science, chemistry, energy, condensed matter physics, nanoscience, biology, biotechnology and pharmacology (Doing 2009; Heinze \& Hallonsten 2017). Finally, big science infrastructures are no longer constrained by national security mandates, and must now compete in a global scientific market with increased mobility, transparency, and competition. As such, they are often in a position of marketing their utility and efficiency across diverse scientific communities and policymakers (Hallonsten 2014; Heidler and Hallonsten 2015).

The softening of a geopolitical ethos does not mean that big science has been purified of excessive political influence, another central concern of Weinberg (Hellström and Jacob 2012; Weinberg 1961, 1963, 1964). On the contrary, public budgets require substantial political support, which may tempt some champions to sell and defend their visions with a certain level of sensationalism (Rainey 2015; Scudellari 2017). Weinberg and other critics were concerned that the business of blockbuster science could undermine the more serious and less sensational work of normal science (Hellström and Jacob 2012).

This has led the observers of big science to seek both more rigorous and holistic evaluations. Here, an obvious point of departure is to evaluate the scientific productivity of big science infrastructures, typically evidenced through citation and patent counts. While quantitative evaluation of these measures is very easy, they are also considered very imperfect proxies of scientific value, as well as poor indicators of the many peripheral benefits of big science infrastructures (Schopper 2016; OECD 2003). As an example, Bianco et al. (2017) argue that the International Space Station, which has cost over $\$ 100$ billion to build and $\$ 2$ billion a year to operate, has, as of 2017, only produced 34 refereed articles and 4 patents. Given their long cycle times, publication and patent counts favour more mature infrastructures and are often used as post-hoc justifications of sunk-cost investments.

Broadening the scope beyond scientific impact, the normal focus for researchers attempting to evaluate the value of big scientific research infrastructures are on the impacts of direct spending on high-tech procurement with subsequent multiplier effects (Autio et al. 2003; Castelnovo et al. 
2018), where evidence suggests that the 'higher' tech procurement has the greatest effect. Schopper (2016), in aggregating numerous studies of CERN, estimates this multiplier to be an average of 4.2 across diverse technology groups; meaning that for every euro spent on high-tech products, an additional 4.2 euros are generated in supporting industries. An additional economic benefit are the subsequent products and services that are direct or indirect derivatives of the technological investments made in conducting the research. These spillover effects are always difficult to estimate, but there is a consensus in the literature that there should be an evaluation of incremental profits (Florio et al. 2016; Castelnovo et al. 2018). Beyond impacts on immediate suppliers, another narrative used to justify investments in scientific research infrastructures are technology spinoffs with the corresponding or assumed, economic growth, job creation, and tax revenue (Aschhoff and Sofka 2009). Here, NASA may be the most prolific example, boasting over 2,000 spinoffs since $1976^{4}$ (NASA Spinoff). The European Space Agency also makes spinoffs a critical theme in its public communication efforts. ${ }^{5}$ Like the early cyclotrons at Berkeley, the value of spinoffs is that they often commercialise technologies in applications outside of a laboratory's principal scientific purview, demonstrating how major research infrastructures can generate impacts beneficial to society without detriment to its main mission (OECD 2014).

Hence, researchers have attempted to derive more holistic models by conceptually defining the alternative social benefits of research infrastructures (Autio et al. 1996). For example, Florio et al. (2016).derive a model that is based on six main dimensions: 1) impact on firms due to technological spillovers produced by access to new knowledge and learning by doing; 2) benefits to employees and students through increases in human capital; 3) the social value of scientific publications for scientists; 4) cultural benefits through outreach activities; 5) additional services provided to consumers; and 6) the value of the scientific discovery

An earlier, complementary perspective, was offered by Autio et al. (2004) who derived a number of propositions related to the positive value that big science infrastructures can have on its ecosystem of suppliers. These include pushing the frontiers of technology and engineering standards, reducing uncertainty surrounding standards and technology investments, sharing their capacity to manage highly complex projects, aggregating highly diverse and specialised knowledge domains towards radical learning and novel combinations, access to international networks, prestige and reputation, network formation, exceptional scale and scope that supports extreme prototyping and testing.

\footnotetext{
${ }^{4}$ https://spinoff.nasa.gov/database/

${ }^{5}$ http://www.esa.int/Our Activities/Space Engineering Technology/TTP2/Highlights/Spin-off.
} 
The general pattern in evaluating investments in research infrastructures is facetiously described by Bozeman: 'when they are being evaluated they reach for indicators that are easy to find and not easy to interpret negatively' (Bozeman 2000 p. 646). However, there is agreement that the indicators that are less ambiguous and readily available are insufficient proxies of what they are measuring (citations and patents as a measure of scientific value), suffer from time-lag effects (scientific knowledge does not have a determinate application or finite lifespan) (Schopper 2016), and are excessively myopic to capture a more holistic picture of the conjectured value (spillover effects, human capital formation, or cultural value.) As argued in Boisot et al. (2011), the more that a research infrastructure deals with fundamental research, the greater the uncertainty surrounding the future value of the outputs. In addition, research infrastructures that are focused on basic science tend to have cultural barriers that are not supportive - and may even be antagonistic - to technology transfer (Rahm et al. 1988; Shapin 2015). In contrast to NASA or ESA, organisations that focus on basic science often have a culture in which the dominant social currency is the generation of scientific knowledge, not technology commercialisation or diffusion (Hammett 1941). The lack of reliable data, or well-understood causality, means that more holistic conceptualisations are excessively difficult to quantify and can lead to politically oriented narratives.

\subsection{Technology transfer without metrics}

An important characteristic of technology spinoffs as a metric of social value is that the benefits are assumed to accrue to society well beyond the immediate scientific community, and this is important in justifying the investments to taxpayers. However, estimating the indirect, or even direct economic impact becomes even more problematic when the technological derivatives are not protected by patents, trademarks, or citations (Schopper 2016), as is often the case. Given that the political mandate of many research infrastructures is to generate scientific knowledge towards greater social value (Hammett 1941), the decision not to protect technologies with property rights is frequent and explicit. These practices are consistent with the ethos of open science and open innovation movements (Chesbrough 2003, 2015; Enkel 2016), as well as specific mandates from funding agencies to make publicly funded research data accessible, with research results published in open access platforms (European Commission 2012). The most famous and recent case was the World Wide Web (specifically HTTP, URL, HTML) when Tim Berners-Lee convinced CERN's managers in 1993 to place it in the public domain and make the IP freely available to everyone. By accepting this, CERN effectively agreed not to draw revenues or economic value from it. In the words of a CERN senior scientific officer: 'In the case of a conflict between revenue generation and dissemination, dissemination takes precedence' (World 
Intellectual Property Organization 2010). For a technology with this level of impact, any quantification of its socio-economic value almost approaches the surreal.

A more recent example of an open technology standard developed at CERN is White Rabbit (Pujol Priego and Wareham 2018). In 2008, scientists and engineers at CERN needed a technology capable of delivering unprecedentedly accurate time synchronisation for their accelerators and detectors. Engineers at CERN were trying to mitigate the problem of limited bandwidth and the impossibility of dynamically evaluating the delay induced by the data links that characterize CERN's geographically distributed computing infrastructure.

Motivated by the purposive engagement of CERN, a group of companies joined in the development of the hardware, software, and drivers for White Rabbit switches and nodes as an open source hardware community. The first adopters of White Rabbit technology were the scientific industry itself; that is, other large-scale scientific facilities which are a sizeable market in their own right. In an unexpected evolution, commercial entities with time-sensitive operations expressed interest. Examples include Vodafone, which conducted a successful proof of concept in 2017 that is considered the world's first successful deployment of White Rabbit in the production network of a commercial telecom operator. In financial services, high-frequency trading (HFT) matching engines based on sequence need to understand order-of-trade execution. White Rabbit is now used by Frankfurt Stock Exchange and Xetra, two of the world's most renowned trading platforms operated by Deutsche Borse Group. As a White Rabbit service provider explains: 'financial transaction organisations are required by law to prove that the time reference used for stamping transactions is UTC (Coordinated Universal Time) traceable. Thus, accuracy required is in the millisecond range, and White Rabbit allows the nanosecond range with high accuracy, allowing legal timestamping applications', (Lipinski et al. 2011).

White Rabbit has also been deployed in other commercial settings: radars and terrestrial approach instrumentation in airports for air traffic control, industry 4.0, autonomous robots, data centres, artificial intelligence and machine learning, smart cities, and autonomous cars. Given the prospects of these domains, White Rabbit will likely have a significant economic impact that will be difficult to calculate via traditional means.

The previous discussion leads to the following conclusions:

1. For research at the forefront of science, a variety of big science organisations have been created with facilities, infrastructures, and instrumentation with unprecedented technical sophistication.

2. Many of these technologies are unavailable in the market and, due to the required scale, must be developed in collaboration with technology suppliers that significantly advance technical and organisational capacities. 
3. In addition to the immediate applications within experimentation and instrumentation, many of these technologies find alternative applications that were not part of their original scope within the scientific facility.

4. Many of these technologies are knowingly not protected by any specific form of IP, nor are their impacts easily identified through available metrics.

\subsection{ATTRACT ${ }^{6}$}

\subsection{Members and objectives}

The ATTRACT consortium is a group of leading European scientific, academic, and industrial organisations. ${ }^{7}$ The core group includes the prestigious scientific research infrastructures working in diverse domains such as: nuclear, particle, and condensed matter physics; life sciences; molecular biology; astronomy; materials science; structural biology; and chemistry. These organisations include the European Organization for Nuclear Research (CERN); European Molecular Biology Laboratory (EMBL); European Southern Observatory (ESO); European Synchrotron Radiation Facility (ESRF); European X-Ray Free Electron Laser Facility (European XFEL); and the Institut Laue-Langevin (ILL). Additional members of the ATTRACT Consortium include Aalto University and ESADE Business School as experts on entrepreneurship, innovation, and commercialisation. Finally, The European Industrial Research Management Association (EIRMA) serves as a liaison to industry.

\subsubsection{Detection and imaging technologies}

To fulfil their scientific aims, these organisations have developed a variety of detection and imaging technologies that are state of the art examples of scientific instrumentation, computation, and analysis. For example, the European X-Ray Free Electron Laser Facility (XFEL) began operations in 2017 and generates up to 27,000 x-ray flashes per second of ultra-short wavelengths that permit the sequential imaging (i.e. filming) of molecular reactions and 3D images at an atomic level. The European Southern Observatory (ESO) is the world's most productive astronomical observatory, having built and operated some of the planet's most sophisticated telescopes ranging across a variety of technology families. Its current flagship project is the Extremely Large Telescope (ELT) planned for completion in 2024, with a performance that is orders of magnitude better than currently existing telescopes capturing visible and near infrared light. In addition to a 39-meter primary mirror composed of 798 individual pieces, the secondary mirror will feature

\footnotetext{
${ }^{6}$ ATTRACT has received funding from the European Union's Horizon 2020 research and innovation programme under grant agreement number 777222.

${ }^{7}$ Detailed information can be found at https://attract-eu.com.
} 
adaptive optics technologies where more than 5,000 actuators distort the mirror's shape 1,000 times per second to compensate for atmospheric disturbances and provide resolution up to 16 times greater than the Hubble space telescope. At CERN, there are four large detectors in the 27-km Large Hadron Collider (LHC) to record and analyse the head-on proton collisions produced by the LHC. The two largest detectors, ATLAS and CMS, are located some 100 metres underground, and record collisions 40 million times a second. The ATLAS detector is 46 meters long, 25 meters in diameter, and weighs about 7,000 tonnes (roughly equivalent to the weight of the Eiffel Tower). It contains some 3,000 km of cables and $100 \mathrm{~km}$ of cryogenic lines. Some 3,000 researchers and students work on the detector, from over 40 countries and 170 universities. The CMS detector is very similar in scale.

The European Molecular Biology Laboratory (EMBL) is one of the world's leading research institutions and Europe's flagship laboratory for the life sciences. Research is conducted by more than 80 independent groups engaging more than 1,700 employees from many nations who work on major challenges in cell biology and biophysics, developmental biology, genome biology, and structural and computational biology, as well as developing relevant technical services and data infrastructures.

The European Synchrotron Radiation Facility (ESRF) hosts the most intense and brilliant hard X-ray source existing today. These are generated by using a dedicated accelerator with a circumference of 844 meters. The facility has 44 highly specialised beamlines, each equipped with state-of-the-art instrumentation. Some 9,000 scientists from around the world visit the ESRF to conduct experiments with the beamlines. Adjacent to ESRF is the Institut Laue-Langevin (ILL) which provides scientists with a very high flux of neutrons feeding some 40 state-of-the-art instruments that are constantly developed and upgraded. As a service institute, the ILL makes its facilities and expertise available to visiting scientists. Every year, about 1,400 researchers from over 40 countries visit the ILL to conduct 640 experiments competitively selected by a scientific review committee in disciplines such as condensed matter physics, chemistry, biology, nuclear physics, and materials science.

\subsubsection{Industrial applications}

The main aim of ATTRACT is to harness and direct exploration towards breakthrough innovation opportunities in detection and imaging technologies, while also offering space for serendipity to stumble onto unforeseen applications. As such, there are no 'intended' technological applications or desired outcomes. Rather, the ATTRACT governance is designed to generate as many options and variety in the applications as possible. That acknowledged, there are some obvious areas where detection and imaging technologies can be employed towards substantial, if 
not paradigmatic, advances in other domains. The following list is adapted from Frost and Sullivan's estimate of the top 50 emerging technologies (Frost \& Sullivan 2017, 2018) which argues that imaging and detection technologies will have core functions in almost all technically sophisticated commercial products, and will constitute an annual market of over $\$ 100$ billion in their own right (Frost \& Sullivan 2015 p. 89).

- Medical devices \& imaging technology: digital pathology, smart pills, nuclear imaging technologies, medical robotics, and neuroprosthetics.

- Lifesciences \& biotechnology: genome sequencing, biosensing, next-gen stem cell, nanofluidics, 3D cell culture systems, biosimilars, and molecular scissors.

- Energy: smart \& microgrid, photovoltaic, advanced energy harvesting, and storage, and heat recovery.

- Advanced manufacturing: micro and nanomanufacturing, agile robots, digital and additive manufacturing, and robotic exoskeletons.

- Sensors \& automation: CBRN detection technologies, biosensors, terahertz sensing, next-gen RTLS, and smart haptics.

- Microelectronics: OLED lighting, flexible electronics, SiC electronics, wireless power transmission, wearables, and cybernetics.

- Materials and coatings: algae-based ingredients, nanocatalysts, advanced filtration, compostable packaging, superhydrophobic coatings, enzyme technology, self-healing technologies, antibacterial coatings, and lightweight composites.

- Environment and sustainability: Waste-to-energy, precision agriculture, microirrigation, off-grid desalination, wastewater filtration.

- Information and communication technology: cloud computing, AI, predictive analytics, virtualisation, cybersecurity.

\subsection{Philosophical foundations}

During the last three decades, policy-makers have increasingly emphasised policies to accelerate innovation and economic growth (Edler and Fagerberg 2017). Three main types of approaches have been developed. The mission-oriented approach aims to support solutions to challenges that are part of an explicit political agenda. Here, policy-makers tend to anchor innovation policies in grand societal challenges such as national defence, climate change, or other sustainable development goals (Galison 2016; Galison and Hevly 1992; Mazzucato 2016; Mazzucato and Semieniuk 2017; Mowery 2012). Invention-oriented approaches aim to stimulate the supply of inventions as derivatives of scientific discovery while leaving any commercial 
exploitation to the market (Bush 1945; Leyden and Menter 2018; Wilson 1991). This was the most widely adopted approach championed post-war by Bush, as policy-makers sought to advance science and technology as broad drivers of geopolitical policy (Galison 2016; Galison and Hevly 1992). Finally, recent decades have seen system-oriented approaches that seek to foster interaction among the different actors taking part of the innovation ecosystem (Borrás and Laatsit 2019; Lundvall 2010; Lundvall and Borrás 2009).

Within these main orientations, a wide range of policy instruments have been deployed in Europe to stimulate innovation (European Commission 2016), and different typologies have been suggested to understand them (e.g. Borrás and Edquist 2013; Edler and Georghiou 2007). The most widely accepted view considers instruments as those focusing either on innovation supply or demand. Supply-side policies stimulate framework conditions and opportunities for innovation to thrive, including measures to support R\&D collaboration, network formation, and incentives to attract highly-skilled labour to focal regions and sectors. For example, in Europe, the Future and Emerging Technologies (FET) programme has allocated $€ 2.7$ billion to pursuing breakthrough ideas through unexplored collaborations of multidisciplinary scientific and cutting-edge engineering teams, indicative of invention-oriented approach mentioned earlier.

Demand-side interventions have been emphasised with greater frequency in the most recent literature (Edler and Georghiou 2007; European Commission 2016; Rolfstam 2009). This perception recognises that the derivatives of basic scientific research have limited value if specific demand-pull mechanisms are not in place to facilitate their entry to the market (Scherer 1982; Schmookler 1962). Demand-side policy instruments include measures to foster investments by private capital (brokering, tech-transfer, IP, subsidies, etc.); or, alternatively, pre-commercial procurement to nurture financial liquidity, investment, and operational scale in start-ups and SMEs (Edler and Fagerberg 2017; Rolfstam 2009). However, instruments that simultaneously stimulate both the supply-side and demand-side dynamics, especially for early stage, high-risk technologies, are less common (Cunningham et al. 2013; European Commission 2016).

The challenge of bridging supply and demand sides of the innovation cycle is not an exclusive concern of innovation policies. It is also a well-known challenge in entrepreneurship research, frequently metaphorized as the valley of death (VoD). This describes the difficult phase in product development and commercialisation where many viable products or start-ups do not survive for a variety of reasons. Typically, these include excessive and unforeseen costs in research, prototyping, testing and manufacturing, limited product development budgets, ineffective coordination and expertise, sub-critical market exposure, and the inability to obtain sufficient internal or external funding to bring the product, or start-up, to a revenue-generating state. Substantial research has focused on the various mechanisms that can be marshalled towards 
mitigating the VoD phenomenon, which include: innovation intermediaries (Islam 2017); scientific parks; technology clusters and living labs (Almirall and Wareham 2011); industry associations (Markham et al. 2010); business incubators and accelerators; technology brokers and tech-transfer functions (Beard et al. 2009); regional, national, and pan-national funding instruments such as Horizon 2020, EIT and ERC of Europe, and NIH, NSF of the US (Hudson and Khazragui 2013). Finally, particularly in medical and life sciences, there has been a growth in initiatives in translational research (Butler 2008). No single VoD scenario is applicable to all technologies. For technologies with high technical readiness levels (TRL) (Banke 2015), the VoD is potentially less fatal, particularly for incremental innovations with probable market uptake. This is typically addressed by risk mitigation functions performed by private investment and venture capital. However, technologies with low TRLs require more extensive interventions, typically with both risk absorption (seed funding and early industry involvement) and risk mitigation (public/private investment mechanisms). It is important to note that TRLs are highly context dependent: the technology may be very mature and tested in its original application at the scientific research installation (high TRL), but immature in a larger system of commercialisation when used in a different sector or market (low TRL) (Héder 2017).

\subsubsection{ATTRACT as novel policy response}

On many dimensions, ATTRACT has been designed to directly address the ineffectual transition - or disconnection - between the technology-push instruments (applied in the early phases) and the technology-pull instruments (the later entry of private capital) (Auerswald and Branscomb 2003; Wolfe et al. 2014). In this respect, ATTRACT is distinctive from recent instruments, such as FET, given that focal actors include both research infrastructures and industrial players, and equal protagonism is given to both supply and demand sides. This is enabled by the pre-existing relationships between research infrastructures and their industrial suppliers; that is, the highly specialised SMEs that have contributed the engineering, construction, and operation in some of the world's most sophisticated technologies. Thus, the industrial relevance and operational feasibility of the projects are verified from the start. Specifically:

1. For projects involving European research facilities and industrial organisations, the most immediate use of their technologies is guaranteed. In this sense, a first 'internal market' is assured.

2. This 'internal market' paves the way for industry to target other applications and new commercial opportunities (i.e. the feasibility of the pilot technologies has been prototyped and tested in the real and demanding working conditions of big science facilities). 
In additional to the $€ 17$ million allocated for seed financing, ATTRACT will facilitate the subsequent participation of equity or loan-based programmes (e.g. European Investment Fund and European Investment Bank). Functional continuity between grant-based programmes and equitybased regimes has, historically, been problematic in European innovation policies (Cunningham et al. 2013; European Commission 2016). So, in this dimension, ATTRACT can be seen as a novel response to the challenge of disconnected policy levers.

Table 1 highlights the main attributes of ATTRACT and how they are positioned relative to traditional EU funding instruments and private capital investments.

Table 1. ATTRACT vs Traditional Funding Types

\begin{tabular}{|c|c|c|c|c|c|}
\hline & $\begin{array}{l}\text { Approach } \\
\text { for crossing } \\
\text { the valley of } \\
\text { death }\end{array}$ & $\begin{array}{l}\text { Risk absorption } \\
\text { (reduce large TRL. } \\
\text { gap) }\end{array}$ & $\begin{array}{l}\text { Risk mitigation } \\
\text { (close TRL gap) }\end{array}$ & $\begin{array}{l}\text { Pre-competitive } \\
\text { market }\end{array}$ & Scaling up \\
\hline ATTRACT & $\begin{array}{l}\text { Considers } \\
\text { that } \\
\text { breakthrough } \\
\text { technologies } \\
\text { need two } \\
\text { steps (risk } \\
\text { absorption } \\
\text { and risk } \\
\text { mitigation). }\end{array}$ & $\begin{array}{l}\text { Public seed funding } \\
\text { to foster 1st ideas } \\
\text { with breakthrough } \\
\text { potential (ca } € 100 k \text { ). } \\
\text { Continuation with } \\
\text { public scale funding } \\
\text { for selected projects } \\
\text { (ca } € 2 M \text { ). }\end{array}$ & $\begin{array}{l}\text { Public/private } \\
\text { investment mechanisms } \\
\text { (e.g. European } \\
\text { Investment Fund, } \\
\text { European Investment } \\
\text { Bank, etc). (3). } \\
\text { Purely private } \\
\text { investment (VC, } \\
\text { corporate, etc). }\end{array}$ & $\begin{array}{l}\text { Ensured in } \\
\text { projects with } \\
\text { participation of } \\
\text { research } \\
\text { infrastructures. }\end{array}$ & \multirow[t]{3}{*}{$\begin{array}{l}\text { Late stage } \\
\text { VC funding } \\
\text { instruments. } \\
\text { Private } \\
\text { equity. } \\
\text { IPO, etc. }\end{array}$} \\
\hline $\begin{array}{l}\text { EU range } \\
\text { public } \\
\text { funding } \\
\text { instruments } \\
\text { (1) }\end{array}$ & \multicolumn{2}{|c|}{$\begin{array}{l}\text { Assumes that only one step is } \\
\text { needed - which is normally risk } \\
\text { mitigation (projects are funded on } \\
\text { equal footing) (2). }\end{array}$} & $\begin{array}{l}\text { Public/private } \\
\text { investment mechanisms } \\
\text { (e.g. European } \\
\text { Investment Funds, } \\
\text { European Investment } \\
\text { Bank, etc). }\end{array}$ & $\begin{array}{l}\text { Not ensured and } \\
\text { depending on a } \\
\text { project-by-project } \\
\text { case. }\end{array}$ & \\
\hline $\begin{array}{l}\text { Private } \\
\text { investment }\end{array}$ & \multicolumn{2}{|c|}{$\begin{array}{l}\text { Focuses on relatively low-risk } \\
\text { technologies with no need for risk } \\
\text { absorption. }\end{array}$} & $\begin{array}{l}\text { Traditional venture } \\
\text { capital funding } \\
\text { Angel/early } \\
\text { stage/venture capital, } \\
\text { etc. }\end{array}$ & Not ensured & \\
\hline
\end{tabular}

The table summarises the comparison between ATTRACT and other funding instruments in their approach towards the crossing of the valley of death for breakthrough technologies.

1. We are referring to EU funding programmes such as Horizon 2020. We do not consider national public funding programmes.

2. Exceptions exist such as the SME instrument https:/ec.europa.eu/programmes/horizon2020/en/h2020-section/smeinstrument. Nevertheless, they differ from ATTRACT because a project needs to apply for seed funding, and subsequently, for scale funding. In ATTRACT the transition between seed and scale is streamlined.

3. http://www.eif.org/; http://www.eib.org/en/index.htm 


\subsubsection{Systemised serendipity}

The assertion that the products of scientific research centres can have value outside of their intended scientific purview is not new. It was demonstrated clearly by Lawrence's early cyclotrons in oncology, and the idea was perhaps best institutionalised as an important policy driver by Bush, who, as a protagonist in American scientific policy, advocated large investments in un-targeted scientific research as a source of serendipitous discoveries or solutions (Bush 1945; Yaqub 2018). In a more liberal interpretation, the Bush legacy favours large investments in research for its unknowable scientific value, as well as numerous unknown benefits that accrue as socio-economic derivatives (education, spin-offs, job creation, etc.)

On the surface, the argument that serendipity can play a positive role in scientific processes and policy has its immediate value as ex-post, anecdotal narratives with limited normative value. However, a methodical attempt to understand serendipity was initiated by Robert Merton (1948) with a dedicated book in 2004 (Merton and Barber 2004). Yaqub (2018) conducted a systematic review of Merton's archives to identify four specific arch-types of serendipity. He organises these according to whether: a) there is a targeted line of inquiry; and b) the type of solution discovered. He defines Walpolian serendipity where a targeted line of inquiry leads to discoveries that researchers were not in search of (solution to a different problem). Mertonian serendipity happens where a desired solution is achieved via an unexpected route (targeted problem - different path). Bushian serendipity is where untargeted exploratory research leads to a solution for a well-known problem. Finally, Stephanian serendipity is where untargeted research finds an unsought solution, that may find future application.

A systematic analysis of serendipity is useful because it offers a more nuanced understanding of its antecedents, conditions, and triggers. Hence, by identifying the formative conditions of serendipity, the design of mechanisms to realise the peripheral benefits of scientific research infrastructures can be improved; in effect, one could attempt to systematise serendipity. While ATTRACT does not seek to constrain itself to any specific type of serendipity, the emphasis is on Walpolian serendipity, where a targeted line of inquiry leads to unsought discoveries (solutions to different problems), and Bushian serendipity, where untargeted research leads to solutions to well-known problems.

In considering a related metaphor, namely, the Pasteur quadrant (Donald Stokes $1997 \mathrm{p}$ 196.), ATTRACT's emphasis is on transitioning from the Bohr quadrant (quest for fundamental understanding, low use-inspired research) to the Pasteur quadrant (quest for fundamental understanding, high use-inspired research.)

However, both frameworks are, at some level, inexact analogies for the ATTRACT project. The focus of ATTRACT is not to generate serendipitous outputs resulting from the findings of the 
basic scientific research (although, this would not be excluded.) Rather, it is to support and systematise the exploration and development of products, services, and businesses that are related to and result from detection and imaging technologies that enable basic scientific research.

\subsubsection{Education and support}

Given that the training of young students in the natural sciences or engineering frequently does not include interdisciplinary or entrepreneurship elements, ATTRACT will work with MSc students at Aalto University and ESADE Business and Law School to explore novel ways to better link scientific and engineering research with applied social challenges and business opportunities. Here, methodologies such as 'design thinking' and other human-centric design philosophies will be employed to understand the negotiated social meanings of technologies (Verganti 2008) and their usage to identify novel, if not disruptive, opportunities to realise social value. These anthropological-focused design methods are frequently used by technology companies (such as IBM, SAP, and IDEO) to understand how technologies are situated in larger system-of-use and social structures, and the technology constraints and affordances made by users. A deeper understanding of these processes is considered core for the realisation of commercial value for a product or service. The creation of interdisciplinary teams of management, law, science, and engineering will complement current MSc training in novel ways. Moreover, it will support the development of entrepreneurial mindsets and business acumen in the more scientifically focused project teams by explicitly bridging the worlds of fundamental science with societal challenges and entrepreneurial opportunity.

\subsection{Governance}

The governance of ATTRACT is designed to separate the key functions and expertise domains of the process and ensure the appropriate checks-and-balances in the project evaluations and key decision points. Membership on a committee is exclusive; that is, no member may sit on more than one committee.

- R\&D\&I Committee (R\&D\&I) is a fully independent committee of top-level experts in the domain of detection \& imaging technology for science, industry, and the private investor community. Their task is to provide objective opinions on the scientific and engineering merit of the proposals submitted.

- The Project Consortium Board (PCB) manages the ATTRACT Project and is the ultimate decision-making body of the Project Consortium. Each institution of the ATTRACT consortium is represented on the PCB (see Section 2.1 on consortium members.) 
- Project Advisory Committee (PAC) comprises leading representatives of international public and private organisations. The committee offers strategic advice on scaling up the ATTRACT Project. In providing such advice, the PAC may establish an open dialogue with public and private stakeholders, including high-level policy-makers and private investors, to raise their interest in investing in and continuing the ATTRACT Project.

- Project Administrative Office (PAO) is the dedicated administrative body for the delivery of the ATTRACT Project.

\subsubsection{Process}

The main steps in the ATTRACT project are as follows.

- An open call was launched to solicit project proposals in the leveraging detection and imaging technologies towards potentially commercially sustainable products or services. While not exclusive, the emphasis was on concepts at technology readiness levels 2-4. The call solicited proposals leveraging four main technology groups: a) sensors; b) data acquisition systems and computing; c) software and integration; and d) front- and back-end electronics. The proposals were a maximum of 3,000 words and included: a) summary; b) project description; c) technology description and external benchmarks; d) envisioned innovation potential (scientific and/or industrial) as well as envisioned social value; e) project implementation, budget, deliverables, and dissemination plan.

- All submissions are to be assessed for technical merit and innovation-potential by the R\&D\&I Committee. Evaluation criteria will include dimensions such as project definition, scope, and technological feasibility, technology state-of-the-art, scientific/engineering merit, industrial potential, commercial feasibility, and social value. The R\&D\&I committee passed its recommendations to the PCB and EC to confirm.

- 170 projects will be awarded $€ 100,000$ for the development of a proof-of-concept or prototype with an application outside of the original purview of the technology, over a period of one year.

- Guidance is provided by the members of the PCB (research infrastructures and business schools) towards technical maturation and business model design and commercialisation.

- ATTRACT will be promoted to business angels, venture capital, and corporate firms to facilitate the transition from public funding to private capital.

- Select and - if relevant - cluster projects with clear potential for industrial implementation. Facilitate transition towards private investment for key projects.

- Diffusion of findings towards a richer European innovation area in which researchers, scientific knowledge, and technology circulate more freely. 


\subsubsection{Submissions}

The call was open from 1 August 1 to 31 October 2018. In that period, 1,211 proposals were received. The following organisation types participated (decreasing order): universities (35\%); SMEs (20\%); research technology organisations (18\%); research institutes (14\%); startups (6\%); other (4\%); and large corporations (3\%). The technology domains of the native technology applications were: sensors (58\%); data acquisition systems and computing (20\%); software and integration (17\%); front- and back-end electronics (5\%).

The top 10 countries represented were: Italy (261); Spain (230); Switzerland (108); France (96); United Kingdome (81); Germany (67); Finland (65); Netherlands (59); Portugal (33); and Austria (26). The submitting consortium sizes were: 2 organisations (810); 3 organisations (294); 4 organisations (78); 5 organisations (22); 6 organisations (5); 7 organisations (1); 10 organisations (1).

At the time of writing, the results of the project evaluations have not been formally released by the European Commission and so cannot be presented here. We can, however, present the results of several workshops conducted prior to the main ATTRACT competition. The objective of the workshops was to test the overall feasibility and reception of the ATTRACT concept with its intended stakeholders (RIs, SMEs, VCs, etc.) and three seminars were conducted during 2016-2017 entitled "Technologies, Wishes, and Dreams" (ATTRACT TWD Symposium). The table below reflects the main classification groups by industrial application. It should be understood that this clustering is derived from the three TWD Symposia and are, we believe, roughly indicative of the ATTRACT outcomes. 
Table 2 Indicative projects from TWD symposia

\begin{tabular}{|c|c|}
\hline Industrial application area & Project examples \\
\hline Medical and biological imaging & $\begin{array}{l}\text { A novel radio-guided surgery for complete tumour resection } \\
\text { Modules for an organ-specific personalised PET scanner }\end{array}$ \\
\hline Radiation detection and monitoring & $\begin{array}{l}\text { Internet of radiation sensors (IoS) } \\
\text { Simple, reliable, low-cost particle dosimetry for cancer therapy using } \\
\text { 3D printing and geant4 simulation }\end{array}$ \\
\hline Intelligent decision systems & $\begin{array}{l}\text { Intelligent decision support system for environmental risk } \\
\text { management } \\
\text { Runtime monitoring for the diagnosis and recovery of complex physical } \\
\text { systems }\end{array}$ \\
\hline Neuro-inspired architectures & $\begin{array}{l}\text { Development of } 3 D \text { associative memory chip } \\
\text { Computer vision aid for the visually impaired }\end{array}$ \\
\hline Cargo and infrastructure inspection & $\begin{array}{l}\text { Video-based drone detection for collision avoidance purposes } \\
\text { CUBIX-highly sensitive radiation imaging detector with fully } 3 D \\
\text { segmentation }\end{array}$ \\
\hline Data management technologies & $\begin{array}{l}\text { Heterogeneous computing for real-time system } \\
\text { Light for wireless data/energy transmission }\end{array}$ \\
\hline Photonics & $\begin{array}{l}\text { Smart pixels for single photons } \\
\text { 2-dimensional materials for single photon counters }\end{array}$ \\
\hline
\end{tabular}

The table represents a clustering snapshot of examples of project proposals presented during:

- $\quad$ 1st ATTRACT TWD Symposium: Barcelona, 30 June-1 July 2016 - ESADE Business School https://indico.cern.ch/event/470460/

- 2nd ATTRACT TWD Symposium: Strasbourg, 4-5 November 2016, https://indico.cern.ch/event/542659/

- $\quad 3 r d$ ATTRACT TWD Symposium: University of Peloponnese in Tripolis, Greece, 31 May-1 June 2017 https://indico.cern.ch/event/609040/

\section{Next phase}

\subsection{Reflections and lessons learned}

The ATTRACT project is consistent with calls by Mazzucato $(2013,2016,2017)$ who argues that the government can go beyond its role as a regulator or fixer of markets, towards an entrepreneurial role, absorbing risk in strategic sectors until technologies have reached a sufficiently mature state to be attractive to private and venture capital. This assumes that market mechanisms and private capital alone may not be the most efficient route to realising innovation via basic to applied research (Martin 2016). Specific industrial policies and stimulus instruments are needed to absorb risk in basic research settings when working with low TRL technologies. This is particularly relevant to ATTRACT in light of empirical research suggesting that, the more the research infrastructure is involved in basic research as part of its mission, the less likely that the organisation will be involved in technology transfer activities (Boisot 2011; Rahm et al. 1988); and this is certainly the case for several ATTRACT partners. 
ATTRACT also resonates with the 'cooperative technology' model of technology transfer described by Bozeman (2000) that assumes government laboratories and research infrastructures can play an important role in technology innovation and economic growth. With some variation, authors such as Mazzucato and Bozeman echo the original doctrine of Vannevar Bush, that basic research has a substantial and positive impact on socio-economic innovation via direct and indirect mechanisms. Interestingly, however, recent literature has argued that while it is commonly believed that Bush maintained an unquestioning faith in an integrated and linear model of innovation, his notion was more sophisticated and involved symbiotic cross-fertilisation (Leyden and Menter 2018). In this view, the authors argue that while Bush saw that basic and applied research benefit each other, they also succeed by working as separate systems, or stacks. Consequently, scientific and economic policy mechanisms should seek to coordinate the two systems, allowing each to operate through its own logic and success criteria, yet simultaneously cultivating specific points where they can nurture each other (Cunningham et al. 2013; European Commission 2016; Leyden and Menter 2018). ATTRACT does not presume to be the definitive word on how to accomplish this coordination task. Indeed, faithful to its genesis in scientific institutions, ATTRACT should be seen as an experiment in innovation policy (Bakhshi et al. 2011). With its focus on the revelation of information and cross-fertilisation of technology and entrepreneurial options, it is experimental at an operational level. With its novel constellation of actors, resources, design, and governance, ATTRACT is very much an experiment in innovation policy. The completion of ATTRACT phase I should lead to insights and findings that inform modifications and extensions to the design of ATTRACT phase II and related initiatives of innovation policy.

\subsection{ATTRACT phase II and beyond}

ATTRACT phase II will aim to take a select group of 6-8 validated projects from ATTRACT phase I and scale them towards technology readiness levels 5-8. ATTRACT phase II is specifically designed to address the intermediate or secondary phases of the valley of death phenomenon which requires greater scalability, maturity, and support. Funding for ATTRACT phase II is currently being negotiated with the relevant funding bodies and is subject to receiving grants. However, current estimates suggest a total funding of €35-40 million. In addition, emphasis will be placed on the transition to public sources of equity-based capital (e.g. European Investment Fund, and the European Investment Bank), as well as private capital sources such as early and late-stage venture capital and private equity.

Beyond phase II, the ATTRACT initiative aims to develop a sustainable European innovation ecosystem strategically interconnected across the area of breakthrough detection and 
imaging technologies (Pennings et al. 2018). It is important to consider that this innovation ecosystem will be formed by two types of organisations with different rationales and economic modalities (publicly funded research infrastructures and privately funded commercial entities)(Jackson 2011). Normally, these two types of organisations and economies are only weakly coupled; resources invested in the research economy must be derived from the commercial economy. Therefore, it will be important to develop adequate public funding instruments that are capable of fostering the incentives driving the research economy and the communities associated with it, and are simultaneously compatible with the financial incentives driving the commercial economy.

The next European R\&D\&I Framework Programme, Horizon Europe, could provide the appropriate conditions. Envisioned funding instruments such as the European Innovation Council (EIC), InvestEU ${ }^{8}$ and VentureEU ${ }^{9}$ foresee the blending of traditional grants with loan and/or equity instruments. The ATTRACT initiative could provide these novel funding instruments with the strategic innovation ecosystem capable of generating value at the single project level, yet more importantly through the synergic cross-fertilisation among projects interconnected under a common technological area. This broader scope is consistent with calls to offer a holistic value proposition that encompasses not just 'out-the-door' technology transfer, but larger social values of education, human capital formation, and cultural enrichment (Autio et al. 2004; Bozeman et al. 2015).

\section{Conclusion}

Europe can boast a long and proud tradition in the advancement of science. As a result, Europe is home to some of the world's most sophisticated scientific research infrastructures, including CERN, European Molecular Biology Laboratory, European Southern Observatory, European Synchrotron Radiation Facility, European X-Ray Free-Electron Laser Facility, Institut Laue-Langevin, and some 600 others. One characteristic of these infrastructures is that they conduct experiments and measurements with unprecedented technological specifications. They do not use off-the-shelf technologies. Rather, they require unique solutions to formidable engineering problems that severely challenge European technology suppliers, and thereby serve as potent drivers of innovation. The detection, imaging, and computational technologies developed for advanced scientific measurement and analysis have tremendous potential for many other highgrowth industries important for Europe - such as advanced manufacturing, medical devices and

\footnotetext{
${ }^{8}$ https://europa.eu/investeu/home en

${ }^{9}$ https://ec.europa.eu/programmes/horizon2020/en/ventureeu
} 
imaging, life sciences and biotechnology, sustainable energy, automation, materials and coatings, microelectronics and ICT. However, the difficulties of transitioning these technologies into commercial products and services are formidable. As such, it is imperative that additional mechanisms and frameworks are developed to provide the supply-side push and demand-side pull mechanisms on these frontier technologies.

In this paper, we have described the ATTRACT project. A novel innovation policy instrument that combines seed funding of $€ 17$ million for 170 projects that leverage the breakthrough imaging, detection, and computational technologies of Europe's leading scientific research infrastructures. We describe the motivation, design, governance, and results to date. If successful, mechanisms and insights from ATTRACT can be leveraged to transform these assets into world-class products and services, driving talent development, employment, economic growth, and social impact.

\subsection{References}

Almirall, Esteve and Jonathan Wareham. 2011. “Living Labs: Arbiters of Midand Ground-Level Innovation." Technology Analysis and Strategic Management 23(1):87-102.

Aschhoff, Birgit and Wolfgang Sofka. 2009. "Innovation on Demand-Can Public Procurement Drive Market Success of Innovations?" Research Policy 38(8):1235-47.

Auerswald, Philip E. and Lewis M. Branscomb. 2003. "Valleys of Death and Darwinian Seas: Financing the Invention to Innovation Transition in the United States." Journal of Technology Transfer 28(3-4):227-39.

Autio, Erkko. 2018. “Digital Affordances, Spatial Affordances, and the Genesis of Entrepreneurial Ecosystems." Strategic Entrepreneurship Journal 12(1):72.

Autio, Erkko, Ari-Pekka Hameri, and Marilena Bianchi-Streit. 2003. Technology Transfer and Technological Learning through CERN's Procurement Activity. Vols. 2003-005. CERN.

Autio, Erkko, Ari Pekka Hameri, and Markus Nordberg. 1996. "A Framework of Motivations for Industry - Big Science Collaboration: A Case Study." Journal of Engineering and Technology Management 13(3-4):301-14.

Autio, Erkko, Ari Pekka Hameri, and Olli Vuola. 2004. "A Framework of Industrial Knowledge Spillovers in Big-Science Centers." Research Policy 33(1):107-26.

Bakhshi, Hasan, Alan Freeman, and Jason Potts. 2011. State of Uncertainty: Innovation Policy through Experimentation. London.

Banke, Jim. 2015. “Technology Readiness Levels Demystified.” Retrieved March 6, 2019 (https://www.nasa.gov/topics/aeronautics/features/trl_demystified.html).

Beard, Randolf T., George S. Ford, Thomas M. Koutsky, and Lawrence J. Spiwak. 2009. “A Valley of Death in the Innovation Sequence: An Economic Investigation." Research Evaluation 18(5):343-56.

Bianco, William, Donald Gerhart, and Sean Nicolson-Crotty. 2017. “Waypoints for Evaluating Big Science*." Social Science Quarterly 98(4):1144-50.

Boisot, Max. 2011. Collisions and Collaboration : The Organization of Learning in the ATLAS Experiment at the LHC. Oxford University Press. 
Borrás, Susana and Charles Edquist. 2013. “The Choice of Innovation Policy Instruments." Technological Forecasting \& Social Change 80(8):1513-22.

Borrás, Susana and Mart Laatsit. 2019. “Towards System Oriented Innovation Policy Evaluation? Evidence from EU28 Member States." Research Policy 48(1):312-21.

Bozeman, Barry. 2000. "Technology Transfer and Public Policy: A Review of Research and Theory." Research Policy 29(4-5):627-55.

Bozeman, Barry, Heather Rimes, and Jan Youtie. 2015. "The Evolving State-of-the-Art in Technology Transfer Research: Revisiting the Contingent Effectiveness Model." Research Policy 44(1):34-49.

Bush, Vannevar. 1945. Science, the Endless Frontier; a Report to the President on a Program for Postwar Scientific Research.

Butler, Declan. 2008. "Translational Research: Crossing the Valley of Death." Nature 453:340-42.

Castelnovo, Paolo, Massimo Florio, Stefano Forte, Lucio Rossi, and Emanuela Sirtori. 2018. “The Economic Impact of Technological Procurement for Large-Scale Research Infrastructures: Evidence from the Large Hadron Collider at CERN." Research Policy 47(9):1853-67.

Chesbrough, H. W. 2003. Open Innovation: The New Imperative for Creating and Profiting from Technology. Boston: Harvard Business School Press.

Chesbrough, Henry. 2015. From Open Science to Open Innovation. Brussels.

Crease, Robert P., Joseph D. Martin, and Peter Pesic. 2016. "Megascience." Physics in Perspective 18(4):355-56.

Cunningham, Paul, Jakob Edler, Kieron Flanagan, and Philippe Larédo. 2013. Innovation Policy Mix and Instrument Interaction: A Review. London.

Doing, Park. 2009. Velvet Revolution at the Synchrotron. Cambridge, Mass.: MIT Press.

Edler, Jakob and Jan Fagerberg. 2017. "Innovation Policy: What, Why, and How." Oxford Review of Economic Policy 33(1):2-23.

Edler, Jakob and Luke Georghiou. 2007. "Public Procurement and Innovation-Resurrecting the Demand Side." Research Policy 36(7):949-63.

Enkel, Ellen et al. 2016. EU Commission, Directorate-General for Research and Innovation: Open Innovation, Open Science, Open to the World.

European Comission. 2012. Comission Recommendation of 17.7.2012 on Access to and Preservation of Scientific Information. Brussels.

European Commission. 2016. Supply and Demand Side Innovation Policies - European Commission. Brussels.

Florio, Massimo, Stefano Forte, and Emanuela Sirtori. 2016. "Forecasting the Socio-Economic Impact of the Large Hadron Collider: A Cost-benefit Analysis to 2025 and Beyond." Technological Forecasting and Social Change 112(November):38-53.

Florio, Massimo and Emanuela Sirtori. 2016. "Social Benefits and Costs of Large Scale Research Infrastructures." Technological Forecasting and Social Change 112(November):65-78.

Frost \& Sullivan. 2015. 2015 Top Technologies in Sensors \& Control (Technical Insights).

Frost \& Sullivan. 2017. "Frost \& Sullivan Unveils Top 50 Multi-Billion Dollar Emerging Technologies That Will Transform the World." Retrieved January 16, 2019

(https://ww2.frost.com/news/press-releases/frost-sullivan-unveils-top-50-multi-billion-dollaremerging-technologies-will-transform-world/).

Frost \& Sullivan. 2018. Top 50 Emerging Technologies: Growth Opportunities of Strategic Imperative Multi-Billion Dollar Technologies Ready to Propel Industries and Transform Our World. 
Galison, Peter. 2016. "Meanings of Scientific Unity: The Law, the Orchestra, the Pyramid, Quilt, and Ring." Pp. 12-29 in Pursuing the Unity of Science: Ideology and Scientific Practice from the Great War to the Cold War, edited by H. Kamminga and G. Somsen. Burlington, VT: Ashgate Publishing.

Galison, Peter and Bruce Hevly, eds. 1992. Big Science: The Growth of Large-Scale Research. Stanford: Stanford University Press.

Giudice, Gian Francesco. 2012. "Big Science and the Large Hadron Collider." Physics in Perspective 14(1):95-112.

Hallonsten, Olof. 2014. "How Expensive Is Big Science? Consequences of Using Simple Publication Counts in Performance Assessment of Large Scientific Facilities." Scientometrics 100(2):483-96.

Hammett, F. S. 1941. “The 'Meaning'; of Science.” Science 93(2425):595-96.

Héder, Mihály. 2017. "From NASA to EU: The Evolution of the TRL Scale in Public Sector Innovation." The Innovation Journal: The Public Sector Innovation Journal 22(2):1-23.

Heidler, Richard and Olof Hallonsten. 2015. "Qualifying the Performance Evaluation of Big Science beyond Productivity, Impact and Costs." Scientometrics 104(1):295-312.

Heinze, Thomas and Olof Hallonsten. 2017. "The Reinvention of the SLAC National Accelerator Laboratory, 1992-2012." History and Technology 33(3):300-332.

Hellström, Tomas and Merle Jacob. 2012. "Revisiting 'Weinberg's Choice': Classic Tensions in the Concept of Scientific Merit." Minerva 50(3):381-96.

Hiltzik, Michael. 2015. Big Science: Ernest Lawrence and the Invention That Launched the MilitaryIndustrial Complex. Simon \& Schuster.

Hudson, John and Hanan F. Khazragui. 2013. "Into the Valley of Death: Research to Innovation." Drug Discovery Today 18(13-14):610-13.

Islam, Nazrul. 2017. "Crossing the Valley of Death-An Integrated Framework and a Value Chain for Emerging Technologies." IEEE Transactions on Engineering Management 64(3):389-99.

Jackson, Deborah J. 2011. What Is an Innovation Ecosystem? Arlington.

Leyden, Dennis Patrick and Matthias Menter. 2018. "The Legacy and Promise of Vannevar Bush: Rethinking the Model of Innovation and the Role of Public Policy." Economics of Innovation and New Technology 27(3):225-42.

Lipinski, Maciej, Tomasz Wlostowski, Javier Serrano, and Pablo Alvarez. 2011. “White Rabbit: A PTP Application for Robust Sub-Nanosecond Synchronization." Pp. 25-30 in 2011 IEEE International Symposium on Precision Clock Synchronization for Measurement, Control and Communication. IEEE.

Lundvall, Bengt Åke. 2010. National Systems of Innovation: Toward a Theory of Innovation and Interactive Learning.

Lundvall, Bengt Ake and Susana Borrás. 2009. "Science, Technology, and Innovation Policy." in The Oxford Handbook of Innovation.

Markham, Stephen K., Stephen J. Ward, Lynda Aiman-Smith, and Angus I. Kingon. 2010. “The Valley of Death as Context for Role Theory in Product Innovation." Journal of Product Innovation Management 27(3):402-17.

Martin, Ben R. 2016. “Twenty Challenges for Innovation Studies.” Science and Public Policy 43(1):432-50.

Mazzucato, Mariana. 2013. The Entrepreneurial State : Debunking Public vs. Private Sector Myths. London \& New York: Anthem Press.

Mazzucato, Mariana. 2016. “From Market Fixing to Market-Creating: A New Framework for 
Innovation Policy." Industry and Innovation 23(2):140-56.

Mazzucato, Mariana. 2018. "Co-Creating and Directing Innovation Ecosystems? NASA's Changing Approach to Public-Private Partnerships in Low-Earth Orbit." Technological Forecasting $\mathcal{E}$ Social Change 136(November):166-77.

Mazzucato, Mariana and Gregor Semieniuk. 2017. "Public Financing of Innovation: New Questions." Oxford Review of Economic Policy 33(1):24-48.

Merton, Robert and Elinor Barber. 2004. The Travels and Adventures of Serendipity. Princeton University Press.

Merton, Robert K. 1948. "The Bearing of Empirical Research upon the Development of Social Theory." American Sociological Review 13(5):505-15.

Mowery, David C. 2012. “Defense-Related R\&D as a Model for 'Grand Challenges' Technology Policies." Research Policy 41(10):1703-15.

NASA. n.d. “NASA Spinoff.” Retrieved December 6, 2018 (https://spinoff.nasa.gov/).

Nobel.org. n.d. "Ernest Lawrence - Biographical - NobelPrize.Org." Retrieved December 4, 2018 (https://www.nobelprize.org/prizes/physics/1939/lawrence/biographical/).

Organisation for Economic Co-operation and Development (OECD). 2003. Turning Science into Business: Patenting and Licensing at Public Research Organisations.

Organisation for Economic Co-operation and Development (OECD). 2014. The Impacts of Large Research Infrastructures on Economic Innovation and on Society: Case Studies at CERN.

Pennings, Roy, Pablo Tello, and Markus Nordberg. 2018. The ATTRACT Programme: A Strategic Proposal for Boosting Breakthrough Co-Innovation on Detection and Imaging Technologies in EuropePreparing the Scence in Phase 1. Geneve.

Pujol Priego, Laia and Jonathan Wareham. 2018. "Time as Service: White Rabbit at CERN." in ICIS 2018 - International Conference on Information Systems. San Francisco: Association for Information Systems.

Rahm, Diane, Barry Bozeman, and Michael Crow. 1988. “Domestic Technology Transfer and Competitiveness: An Empirical Assessment of Roles of University and Governmental R\&D Laboratories." Public Administration Review 48(6):969-78.

Rainey, Kristine. 2015. “ISS Benefits for Humanity.” Retrieved December 5, 2018 (https://www.nasa.gov/mission_pages/station/research/benefits/index.html).

Rolfstam, Max. 2009. "Public Procurement as an Innovation Policy Tool: The Role of Institutions." Science and Public Policy 36(5):349-60.

Scherer, F. M. 1982. “Demand-Pull and Technological Invention: Schmookler Revisted." The Journal of Industrial Economics 20(3):225-37.

Schmookler, Jacob. 1962. "Economic Sources of Inventive Activity." The Journal of Economic History 22(1):1-20.

Schopper, Herwig. 2016. "Some Remarks Concerning the Cost/Benefit Analysis Applied to LHC at CERN." Technological Forecasting and Social Change 112(November):54-64.

Scudellari, Megan. 2017. “Big Science Has a Buzzword Problem.” Nature 541(7638):450-53.

Shapin, Steven. 2015. “The Desire to Know: Scientific Virtue Is Worth Saving." The Boston Review 32(January-February).

Verganti, Roberto. 2008. “Design, Meanings, and Radical Innovation: A Metamodel and a Research Agenda." Journal of Product Innovation Management 25(5):436-56.

Weinberg, Alvin M. 1961. “Impact of Large-Scale Science on the United States." Science 134(3473):161-64. 
Weinberg, Alvin M. 1963. “Criteria for Scientific Choice.” Minerva 1(2):159-71.

Weinberg, Alvin M. 1964. “Criteria for Scientific Choice II: The Two Cultures.” Minerva 3(1):3-14.

Wilson, D. A. 1991. “The Vannevar Bush Legacy." Science 251(4990):210.

WIPO. 2010. "Managing IP at CERN." WIPO Magazine. Retrieved

(https://www.wipo.int/wipo_magazine/en/2010/06/article_0003.html).

Wolfe, Amy K., David J. Bjornstad, Barry L. Shumpert, Stephanie A. Wang, W. Christopher Lenhardt, and Maria Fernanda Campa. 2014. "Insiders' Views of the Valley of Death: Behavioral and Institutional Perspectives." BioScience 20(10):1-7.

Yaqub, Ohid. 2018. “Serendipity: Towards a Taxonomy and a Theory.” Research Policy 47(1):16979.

Yarris, Lynn. n.d. "Ernest Lawrence's Cyclotron." Berkeley Lab Science Articles Archive. Retrieved December 4, 2018 (https://www2.lbl.gov/Science-Articles/Archive/early-years.html). 


\section{ESADE}

Ramon Llull University

Campus Barcelona · Pedralbes

Av. Pedralbes, 60-62

08034 Barcelona (España)

T. +34 932806162

F. +34 932048105

Campus Barcelona · Sant Cugat

Av. de la Torreblanca, 59

08172 Sant Cugat del Vallés

Barcelona (España)

T. +34 932806162

F. +34 932048105

\section{Campus Madrid}

Mateo Inurria, 25-27

28036 Madrid (España)

T. +34 913597714

F. +34 917030062

www.esade.edu 